Published in final edited form as:

Curr Hepatol Rep. 2019 June ; 18(2): 206-215. doi:10.1007/s11901-019-00468-y.

\title{
Testing for Hepatitis $\mathbf{C}$ in Pregnancy: the Time has Come for Routine Rather than Risk-based
}

\author{
Tatyana Kushner ${ }^{1}$, Catherine A Chappell ${ }^{2}$, Arthur Y Kim ${ }^{3}$ \\ ${ }^{1}$ Division of Liver Diseases, Icahn School of Medicine at Mount Sinai, One Gustave L Levy Place, \\ Box 1123, New York, NY, 10029 \\ ${ }^{2}$ Department of Obstetrics, Gynecology and Reproductive Sciences, University of Pittsburgh \\ School of Medicine, 300 Halket Street, Pittsburgh, PA 15206 \\ ${ }^{3}$ Division of Infectious Diseases, Massachusetts General Hospital and Harvard Medical School, \\ 55 Fruit Street Cox 6, Boston, MA 02114
}

\begin{abstract}
Purpose of review: The purpose of this review is to discuss the reasons for HCV testing during pregnancy and to review what is known about antiviral treatment during pregnancy.

Recent findings: Hepatitis $\mathrm{C}$ virus affects over 3 million persons in the United States and is one of the leading infectious causes of death. While HCV is most commonly transmitted via parenteral exposures, thus affecting people who inject drugs, it is also transmitted from mother-to-child. Due to an expanding opioid crisis, an increasing number of women of childbearing age are now infected, resulting in transmission to infants. Risk-based screening has never been proven effective and thus universal screening of pregnant women for $\mathrm{HCV}$ infection has been recommended.
\end{abstract}

Summary: Obstetricians may play a key role in the U.S. by implementing universal testing for $\mathrm{HCV}$ in pregnant women, thereby enhancing the health of mothers and identifying children at risk.

\section{Keywords}

hepatitis $\mathrm{C}$ virus; pregnancy; perinatal transmission; antiviral treatment; testing

\section{Introduction}

\begin{abstract}
After acute infection with hepatitis C virus (HCV), a proportion of infected individuals clear spontaneously, with higher clearance rates among those who are younger and female [1]. Both the acute phase and chronic phase of HCV infection are usually asymptomatic or
\end{abstract}

\footnotetext{
Terms of use and reuse: academic research for non-commercial purposes, see here for full terms. http://www.springer.com/gb/openaccess/authors-rights/aam-terms-v1

Corresponding Author: Arthur Y. Kim, akim1@mgh.harvard.edu.

Publisher's Disclaimer: This Author Accepted Manuscript is a PDF file of a an unedited peer-reviewed manuscript that has been accepted for publication but has not been copyedited or corrected. The official version of record that is published in the journal is kept up to date and so may therefore differ from this version.

Human and Animal Rights and Informed Consent

This article does not contain any studies with human or animal subjects performed by any of the authors.
} 
minimally symptomatic. Chronic $\mathrm{HCV}$, once established, is associated with a variable rate of liver fibrosis, resulting in future risk of advanced fibrosis and cirrhosis, as well as hepatocellular carcinoma, typically over three or more decades, and is associated with significant lost life expectancy [2]. HCV is the leading single infectious cause of death in the United States, outpacing 60 other reportable infectious conditions (including HIV and tuberculosis) combined [3].

Over the past decade the epidemiology of hepatitis C (HCV) in the United States has demonstrated a dramatic shift as a result of the opioid epidemic, with an increasing number of new HCV cases reported among young persons who inject drugs (PWID) [4]. Rates of new HCV infections reported among women aged 15-44 have surpassed rates among "baby boomers," born between 1945 and 1965, and are continuing to rise. As a result of a rising burden of HCV reported among women of childbearing age as well as in children nationally, the concern for increasing rates of mother-to-child transmission of HCV has been raised [5].

As a result of increased prevalence of $\mathrm{HCV}$ in reproductive-aged women, more women with $\mathrm{HCV}$ will become pregnant and for many of them, obstetrical care will be their primary encounter with the health system. Thus, pregnancy may represent an ideal opportunity to initially diagnose $\mathrm{HCV}$ in women, link them to care, and refer them for HCV treatment. Recently, the American Association for the Study of Liver Diseases (AASLD) and the Infectious Disease Society of America (IDSA) have jointly recommended universal screening for HCV among women during pregnancy [6]; however, the Society for Maternal Fetal Medicine still recommends risk-based screening for HCV during pregnancy [7]. In the setting of conflicting recommendations, as well as differing practices across obstetricians, the opportunity to diagnose and treat new $\mathrm{HCV}$ cases during pregnancy may be missed, potentially leading to mother-to-child transmission and missed diagnosis of $\mathrm{HCV}$ infection among infants, as well as progression of $\mathrm{HCV}$ in women. As a result, this missed opportunity would hamper efforts towards the potential elimination of $\mathrm{HCV}$ as a public health problem. Here we advocate for why universal screening during pregnancy should become a universal recommended component of obstetrical care.

\section{An epidemic of HCV in women of childbearing age}

The national opioid crisis has directly shifted the epidemiology of HCV from being largely a disease among baby boomers to becoming a disease of young adults. In an early report from the Centers for Disease Control and Prevention (CDC), the state of Massachusetts reported an overall decline in cases of HCV from 1992 to 2005 [8]. However, on closer look it was noted that during that during 2002 to 2006, there was actually an increase among cases in 2002 to 2006 among young adults aged 15 to 24 , leading to enhanced surveillance in this age group. From 2007 to 2009, the number of cases continued to increase particularly among non-Hispanic white persons, demonstrating a bimodal age distribution of HCV infection in 2009 (compared to the unimodal age distribution in 2002 pertaining to persons born in 1945-1964). While the timing of the increased incidence in young persons may vary by region, multiple national and state level evaluations have subsequently confirmed similar findings $[9,10]$. 
In 2010, the Wisconsin Division of Public Health identified a 300\% increase in HCV cases per year in six rural counties in persons aged $<30$ from 2004-2008 to 2009-2010. The majority of the individuals diagnosed with HCV reported injection drug use [11]. This epidemic of increasing $\mathrm{HCV}$ cases among young persons particularly in rural settings was investigated on a national scale, and again 34 states reported higher incidence of $\mathrm{HCV}$ in 2012 compared to 2006 [4]. Of note, 52\% of newly reported HCV infections occurred among women. This is consistent with a shift in demographics of opioids, as the 1960s/70s disproportionately affected men; however, the current epidemic affects women equally to men [12]. As a result, the CDC examined surveillance date for acute $\mathrm{HCV}$ in conjunction with the Treatment Episode Data Set-Admissions (TEDS-A), which contains data on admissions to substance abuse treatment facilities, and again found an increase from 2006 to 2012 in Kentucky, Tennessee, Virginia, and West Virginia, which correlated with an increased number of admissions to substance abuse treatment for opioid dependency programs [13]. Interestingly, in urban settings from these states, there were more cases of acute $\mathrm{HCV}$ reported among women then in men, despite similar rates between women and men in nonurban settings.

Women who inject drugs may actually be at higher risk of acquiring HCV then men. In a large systematic review examining HCV incidence among persons who inject drugs (PWIDs), women were 36\% more likely to contract HCV from injection drug use then men [14]. Proposed reasons for this difference include behavioral as well as biological factors that may predispose females to higher risks of acquiring HCV. Behavioral risks include increased susceptibility towards stigma and thus lower participation in harm reduction services among women as well as higher risk injection behaviors, such as increased sharing of needles. In a further evaluation of injection behaviors utilizing the InC3 Collaborative cohort, a higher HCV incidence in women was identified in women with reported receptive syringe sharing and ancillary equipment sharing, although these practices did not differ between men and women [15]. More studies of female PWID are necessary regarding differential access to harm reduction, gender-power dynamics, and/or social networks that account for this finding.

Although some of these data reporting increases in HCV over time may reflect increased testing and reporting on the part of providers, the parallel increase in substance use treatment suggests a true increase in HCV infection rate as a result of injection drug use. In addition, in an evaluation of data from the National Survey on Drug Use and Health (NSDUH) from 2007 to 2014, women were noted to have increasing heroin use over time at a faster rate than men and decreasing nonmedical use of a prescription opioids at a slower rate than men. Thus, gender-specific efforts to address the opioid epidemic need to be developed in order to decrease injection drug use and consequent $\mathrm{HCV}$ infection [16].

Given the increased incidence of HCV infection among women of childbearing age, reports have also evaluated HCV infection during pregnancy specifically, and found similarly alarming trends. Utilizing state surveillance data in Wisconsin and linking to Medicaid data with birth information, from 2011 to 2015, a 93\% increase in HCV diagnosed during pregnancy was noted [17]. Similarly in a recent report published in from Ohio, during a 10year study period from 2006 to 2015, the rate of maternal HCV infection during pregnancy 
increased $631 \%$ [18]. Utilizing national birth certificate data, HCV infection present at the time of delivery among pregnant women increased by $89 \%$ from 2009 to 2014, with rates as high as 22.6 per 1000 liver births in West Virginia and 10.1 in Tennessee [19]. Factors associated with risk of $\mathrm{HCV}$ during pregnancy included cigarette smoking, Medicaid insurance, and white, non-Hispanic race. Co-infection with other viruses including hepatitis B and other sexually transmitted infections were also strongly associated.

With increased rates of HCV among pregnant women, increased rates of mother-to-child transmission have also been documented. In the Wisconsin study, although only $34 \%$ of infants received recommended $\mathrm{HCV}$ testing, $7 / 31$ (22\%) of those who actually received appropriate testing had documented HCV transmission (4\% of the total number of infants born) [17]. On a national scale utilizing Quest laboratory data, $0.73 \%$ of pregnant women (CI, $0.69 \%$ to $0.78 \%$ ) were estimated to have HCV infection from 2011 to 2014, and with 3.9 million live births annually, and an estimated rate of mother-to-infant transmission of $5.8 \%$, an estimated 1700 infants (CI, 1200 to 200 infants) were born with HCV infection each year to 29,000 women [5]. Taken together, the rise in HCV among reproductive-aged women has led to increased HCV infection during pregnancy as well as mother-to-child transmission of HCV. Enhanced detection of HCV during pregnancy with universal screening would allow for increased diagnosis of $\mathrm{HCV}$, improved follow up of children born to mothers with $\mathrm{HCV}$, as well as potentially decreased mother-to-child transmission through specialized approaches to obstetrical management to minimize risk of infection. Although the mode of delivery (vaginal versus cesarean birth) does not affect the risk of transmission, and $\mathrm{HCV}$ is not transmitted via breastfeeding, obstetricians can minimize the use of amniotomy, fetal scalp electrode monitoring, episiotomy and/or operative delivery (forcepsassisted or vacuum-assisted vaginal delivery) that may increase the risk of perinatal HCV transmission.

The natural history of HCV following perinatal transmission may be benign, as almost half of infected children will spontaneously clear, and only a minority progress to cirrhosis during childhood [20]. However, a recent study demonstrated that individuals who acquire hepatitis $\mathrm{C}$ through mother-to-child transmission develop cirrhosis at younger ages and higher rates than individuals who acquire HCV later in life [21]. For those chronicallyinfected, treatment of children is being studied, with future prospects of application of antiviral treatment as young as age 3 . Despite this benign course during childhood, HCVinfected children will be at eventual risk for HCV-related complications and children are unlikely to be proactively identified without knowledge of the status of their mother [22]. In Philadelphia, only $16 \%$ of perinatally-exposed children had HCV testing [23]. Another recent study based on billing codes confirmed that only a fraction of infants born to HCVinfected mothers were tested: among $1025 \mathrm{HCV}$-exposed infants, 323 (31\%) had record of receiving well-child services, and among these, only 96 (30\%) were properly screened for HCV [24].

\section{Pregnancy and HCV}

Liver fibrosis in women generally progresses more slowly than men, possibly related to antifibrotic effects of estrogens or lower rates of alcohol use [25]. Postmenopause, the 
protective effect of female gender on liver fibrosis appears to be attenuated unless hormone replacement therapy is administered [26, 27]. Given the timeframe until cirrhosis, it is unlikely that $\mathrm{HCV}$-infected women of childbearing age will present with end-stage liver disease during pregnancy. However, women infected with HCV should receive postpartum antiviral treatment regardless of fibrosis stage, which if successful abrogates future risk of HCV-related liver disease and liver cancer as well as the onward risk of transmission.

Identifying more pregnant women with $\mathrm{HCV}$ would compel obstetricians to provide appropriate counseling regarding the impact of $\mathrm{HCV}$ on pregnancy, especially if specialist help is not immediately available. Key studies regarding the natural history have been recently reviewed [7]. Negative obstetric outcomes were found to be associated with HCV, including cesarean delivery, fetal intolerance of labor, preterm birth, maternal intensive care unit admission, blood transfusion, small for gestational age, and neonatal intensive care unit admission $[28,29]$. While a rare event, the potentially serious complication of intrahepatic cholestasis of pregnancy (ICP) may occur up to 20 -fold more often in $\mathrm{HCV}$-infected women compared to uninfected women [30]. Therefore, not only has HCV been increasingly recognized among women during pregnancy, but also has been associated with worse maternal and fetal outcomes. Although associated features such as injection drug use, socioeconomic status, and other concomitant health risks may be contributing to negative pregnancy outcomes, direct effects of $\mathrm{HCV}$ infection on pregnancy likely plays a role as well.

Conversely, pregnancy also impacts the natural history of HCV. Nulliparity has been associated with faster fibrosis progression [26]. When following women longitudinally through pregnancy, increases in HCV RNA levels and decreases in ALT have been noted, suggesting a more "relaxed" immune response [31]. Postpartum spontaneous clearance of chronic infection has also been reported, likely due to a surge of immunity following childbirth $[32,33]$. The vast majority of women with chronic infection during pregnancy are likely to have ongoing infection postpartum and, if left untreated, are likely to suffer sequelae.

Chronic HCV as a condition exhibits several characteristics that make screening attractive: (1) a long latent period that is largely asymptomatic before severe manifestations, (2) availability of relatively simple testing (blood testing of anti-HCV antibody then confirmatory HCV RNA), (3) determination of its presence is important for the patient's prognosis and informs those at risk for transmission (in this scenario the infant), (4) patient knowledge of the infection can be improved; and (5) identification of infection leads to an opportunity to intervene and cure the condition.

\section{Prospects for antiviral treatment during pregnancy}

As mentioned previously, a prime reason why screening is attractive is the ability to intervene in the natural history of $\mathrm{HCV}$ infection. Moreover, the interventions have evolved substantially in recent years, moving from a toxic injectable interferon-based regimen to a safe, oral, interferon-free regimen. During the interferon era, it was difficult to recommend treatment fraught with side effects to postpartum mothers, who were usually decades away 
from complications. Also, ribavirin conferred teratogenic risk. In contrast, the October 2014 Food and Drug Administration (FDA) approval of the first ribavirin-free directly acting antivirals (DAAs) the fixed dose combination of the NS5B polymerase inhibitor sofosbuvir (SOF) and the NS5A inhibitor ledipasvir (LDV) marked a revolution in HCV therapy and a novel opportunity for treatment of HCV during pregnancy. The fixed dose combination of LDV (90 mg) and SOF (400 mg) has a sustained virologic response (SVR) of approximately 99\% and 94\%, respectively, when given as a once-a-day pill for either 12 or 8 weeks to treatment-naive HCV genotypes 1, 4, 5, and 6 patients without cirrhosis. For FDA approval evaluation in pregnancy is not required, however preclinical studies of pregnant rats and rabbits showed there were no safety concerns for antenatal administration. In fact, LDV/SOF was originally given a pregnancy category B designation [34]. Since 2014, other DAAs have been approved that provide improved coverage of $\mathrm{HCV}$ genotypes 2 and 3, specifically, sofosbuvir/velpatasvir, daclatasvir (co-administered with SOF), and glecaprevir/pibrentasvir. None of these medications are known to cause any fetal toxicities in preclinical studies at weight-adjusted doses higher than those administered in humans for HCV treatment, except when the dose was high enough to produce maternal toxicity as well [35-37]. Considering that all the mentioned DAAs are given for only 8 to 12 weeks, it is possible to give a complete course before delivery if started in the late second trimester. This strategy would preclude administration of DAAs during organogenesis, which is completed at 16 weeks of gestation and therefore minimize the risk of teratogenicity, while still giving ample opportunity for maternal $\mathrm{HCV}$ cure and prevention of $\mathrm{HCV}$ perinatal transmission to the infant. A recent survey of $\mathrm{HCV}$-infected mothers suggested that prevention of transmission to their infants may be a greater motivator to pursue antiviral therapy during pregnancy than their personal cures [38].

The first step towards the evidence-based use of any medical intervention during pregnancy are small Phase 1 pharmacokinetic (PK) studies performed under an FDA Investigational New Drug Application. Significant physiologic changes occur during pregnancy that affect drug absorption, distribution, metabolism and excretion, resulting in PK changes with may have clinical consequences [39]. For example, increased renal clearance of drugs could lead to suboptimal concentrations with standard dosing, leading to potential antiviral resistance or decreased efficacy. The Food and Drug Administration (FDA) recommends that a Phase 1

PK study in pregnancy be conducted for medications if: 1) all preclinical and clinical studies to date provide reassuring data regarding the safety of use during pregnancy and 2) this risk to the fetus is not greater than minimal and the purpose of the research is of important biomedical knowledge [40]. These criteria are met for the study of any of the aforementioned HCV DAAs.

The first phase one PK study of LDV/SOF during pregnancy (NCT02683005) initiated a course of LDV/SOF at 23 to 24 weeks' gestation and continued for 12 weeks. Three intensive PK visits occurred between 25 and 27, 29 and 31, and 33 and 35 weeks' gestation. After delivery, the infants will be followed for an entire year with growth assessments, developmental exams and HCV testing [41]. Nine women were treated with 12 weeks of LDV/SOF, with initial results revealing: (1) LDV/SOF was well-tolerated, (2) no significant concerns with efficacy or safety have been detected thus far and (2) 8 out of 8 women with evaluable data achieved SVR. Pharmacokinetic data are pending [42]. After ensuring the 
appropriate dose, larger studies are still needed to determine if antenatal DAA administration and at what gestational age time is safe and effective for both maternal treatment as well as prevention of perinatal $\mathrm{HCV}$ transmission. Although maternal outcome data regarding the Phase 1 PK study of LDV/SOF will be available soon, a similar small PK study of a pangenotypic regimen is need prior to a larger study of antenatal HCV treatment. A pangenotypic DAA regimen is preferable to LDV/SOF given the significant prevalence of genotype 3 infection among young persons who use injection drugs [43].

Key points regarding the epidemiology, natural history and treatment relevant to pregnancy are listed in Table 1.

\section{Risk-factor based screening versus universal screening}

Testing for HCV infection involves two stages: an initial screening antibody (anti-HCV) for exposure; if positive, followed by HCV RNA testing typically by real-time PCR. This twostage testing adds the complexity of a follow-up blood draw; however, many laboratories now offer "reflex" testing: positive anti-HCV results to have automatic HCV RNA from the same specimen. If two visits are required, many patients who are positive by antibody never receive $\mathrm{HCV}$ testing, whereas reflex testing is likely to improve the receipt of important results and enhance subsequent linkage to specialized care [44].

Arguments against maternal testing for HCV based on natural history are that the effects of $\mathrm{HCV}$ on pregnancy are not uniform, may be confounded by other factors, or are rare (in the case of ICP). Also, while HCV is ultimately a serious infection, following mother-to-child transmission chronic infection rarely leads to significant liver disease during childhood. Significant liver-related events are generally decades away for both mother and child. An additional argument against maternal testing for $\mathrm{HCV}$ may be made based on the lack of data to support antiviral treatment during pregnancy. It is notable that universal screening for HBV for pregnant women was recommended by the CDC prior to the approval of antiviral agents such as lamivudine and well before their antepartum use during pregnancy [45]. Nonetheless, recent SMFM guidance [7] is in agreement with AASLD/IDSA that it is worthwhile to diagnose $\mathrm{HCV}$ due to its importance for both the future health of the mother and for the identification of infants who may become infected. There is only discordance regarding the precise approach, namely risk-factor based versus universal screening.

Risk factor-based screening requires ascertainment of past exposures in several categories (Table 2). Some exposures should be rare in women of childbearing age, such as receipt of long-term hemodialysis. Those receiving transfusions before July 1992 and clotting factor concentrates before 1987, should be rare, as many are now beyond childbearing potential; those in this category would likely be limited to those exposed as children who may be unaware of such exposures. Screening based on alanine aminotransferase (ALT) misses $\mathrm{HCV}$-infected women with values within the normal range (up to $46 \%$ of infected individuals) [46]; also, ALT is not a routine test during pregnancy. More commonplace would be women who ever injected illegal drugs (even once), women who used intranasal illicit drugs [47], women with past history of incarceration, and those who have sought evaluation for sexually-transmitted infections such as HIV. 
If the goal is to apply effective screening, strategies based on risk-factor screening unfortunately misses the mark largely because it has never been shown to be successful in the United States. A recent retrospective data analysis of electronic medical records (EMR) for 1426 women presenting for antenatal care in 2016 noted that only $7 \%$ were tested for HCV. Of note, 21/40 women with intravenous drug use documented in the EMR were not tested; also, $10 \%$ of $\mathrm{HCV}$ positive pregnancies had no evidence of a risk factor [48]. The failure of risk-factor based screening is not at all unique to the obstetrical setting, as the literature indicates that other providers similarly failed to successfully diagnose HCV using this approach $[49,50]$.

What are reasons for failure of risk-factor based testing? Provider-related barriers include time needed to ask such detailed questions, lack of knowledge regarding HCV risk factors and transmission, and competing priorities. Patients may not wish to report certain behaviors particularly during pregnancy especially surrounding drug use due to stigma, fear of recrimination, and/or because they occurred in the distant past. While it may be obvious to test pregnant women already involved in care for opioid use disorders [51], less obvious and/or past behaviors may not be reliably ascertained especially as self-reporting of smoking, alcohol, and drug use has not proven to be accurate [52, 53]. Use of questionnaires regarding $\mathrm{HCV}$ risk factors may reduce provider time and from the patient perspective may reduce stigma, but when applied to pregnant women in a high-risk urban clinic was not sufficient to capture cases [54].

Data regarding universal screening approaches in the context of the recent opioid epidemic are emerging. Recently Norton Healthcare, centered in Louisville, Kentucky, responded to an increase in opioid use and the attendant risk for infectious complications such as HCV by implementing universal screening of pregnant women, via a standing order in their EMR for prenatal visits. The testing strategy included reflex HCV RNA testing for positive antibody tests. The authors compared in time-series fashion the previous period when risk-based testing was applied to the study period. HCV testing rates rose from $17.9 \%$ during riskfactor based screening to $100 \%$ during the universal screening. The rate of positive antibodies was not very different ( $4.3 \%$ risk-factor based versus $4.9 \%$ universal), but the rate of confirmatory HCV RNA was markedly increased (54.3\% to 100\%). Ultimately almost ten times as many women with positive HCV RNA were identified (31 women during riskfactor based screening, 306 during universal screening). It is unlikely that temporal increases in local incidence alone could account for this difference, which is much more easily explained by improvements in the total number of women receiving proper testing [55].

Issues regarding universal testing and measures that may mitigate these concerns are listed in Table 3. If testing rates rise due to universal application among pregnant women, the number of anti-HCV positive / HCV RNA negative individuals will increase in parallel. This pattern generally represents one of 3 possibilities: (1) false positive; (2) spontaneous clearance; (3) transient clearance, usually during acute infection. Recombinant immunoblot assays were used in the past to attempt to inform the difference between true and false positive anti-HCV but are no longer commercially available. Although anti-HCV testing has excellent sensitivity and specificity, increased testing of lower risk individuals will result in a parallel uptick in the magnitude of false positives. It is safe to counsel that in those with risk 
factors, the likelihood of true positive is increased and in those without risk factors, it is decreased. For those without traditional risk factors listed above, the possibility of childhood exposure from contaminated medical equipment and/or transmission and in utero exposure and subsequent clearance may be considered; the latter is a possibility due to the high prevalence in their mothers' "baby-boomer" generation. In any event, the scenarios of false positive or spontaneous clearance each convey the same message: there is no current infection that requires treatment or confers risk to the newborn.

An argument against universal screening is that increased identification of HCV may lead to incorrect decisions, such as recommending against vaginal birth or breastfeeding. Knowledge gaps regarding HCV have been identified for both patients [56] and providers [57]. Health systems considering universal screening can co-implement education to help prevent these issues [58].

Another concern is that universal prenatal screening may be associated with increased cost. Risk factor-based screening may save costs regarding laboratory testing, reducing the total number of women testing but also increases provider time spent ascertaining risk. The primary screening test for anti-HCV antibodies is relatively cheap, comparable to HIV and $\mathrm{HBV}$ testing. Costs of the care of $\mathrm{HCV}$-infected pregnant women include vaccination for hepatitis A virus (considered safe in pregnancy), testing for associated conditions (such as HIV, HBV) [7], and postpartum antiviral treatment. Fortunately, testing for HIV and HBV is already routinely universal for pregnant women. Also, due to competition and negotiations with payors, costs of $\mathrm{HCV}$ antiviral regimens are significantly decreasing [59]. A recently published cost-effectiveness model suggests that universal prenatal HCV testing would improve health outcomes, conferring benefits to HCV-pregnant women by their living 1.21 years longer, improved identification of $\mathrm{HCV}$ exposure for neonates, and had an incremental cost-effectiveness ratio (ICER) of 41,000 USD/quality-adjusted life year (QALY) gained, well under commonly accepted thresholds [60]. A separate analysis assumed a lower cost of treatment (25,000 USD) and found that universal antenatal screening had a mean ICER of only $\$ 2,826$ for every QALY gained; this model also projected that for the United States about 33,000 more women would be identified [61].

If women with $\mathrm{HCV}$ are successfully identified by obstetricians during pregnancy, they may face barriers to receipt of postpartum treatment, which include geographic distance to specialists and insurer restrictions by fibrosis stage and/or sobriety. Novel models of delivering $\mathrm{HCV}$ care, including treatment by primary care providers with specialist help via telemedicine or other models can help overcome geographic barriers [62]. Insurer restrictions in certain regions disproportionately affect Medicaid populations that have higher prevalence of HCV [63]. However, these and other restrictions are steadily being lifted as well as challenged by advocacy and in the courts [59]. Even without postpartum treatment, knowledge of infection confers several benefits, as reviewed above. To maximize follow-up of exposed infants and enhancing the effectiveness of maternal testing, communication between the maternal care team and pediatricians is essential and can be augmented by public health programs similar to those for maternal HBV. 
Acknowledging these concerns, the choice to continue risk-factor based screening maintains a status quo of an unproven strategy that apparently is ineffective at identifying HCV-

infected mothers and therefore infants at risk. Universal screening of pregnant woman is one proposal that may be bundled with HIV and HBV testing, may be simplified via reflex testing, is cost effective, and ultimately much more efficacious in identifying an important condition that has significant implications for both mother and child.

\section{Conclusion}

The opioid epidemic has resulted in rising incidence of $\mathrm{HCV}$ in women of childbearing age. Pregnancy represents a unique opportunity to test for HCV, which has potential benefits for maternal, child, and public health. Knowledge of HCV status is a crucial step towards linking the mother to postpartum antiviral treatment and testing of the exposed newborn. Treatment of HCV during pregnancy is not yet recommended. By implementation of universal testing, obstetricians can play major roles in identifying HCV among mothers and their children and linking those with infection to curative treatment, thereby partnering towards the elimination of $\mathrm{HCV}$ in the United States.

\section{Acknowledgments}

Conflicts of Interest

Catherine A. Chappell has received research funding from Gilead Sciences and Merck though Magee-Womens Research Institute (MWRI) and has served as a consultant for Gilead Sciences. Arthur Y. Kim served as a consultant for Biomarin, Inc. Tatyana Kushner reports personal fees from Gilead Sciences for participation in a scientific advisory board, outside the submitted work.

\section{References}

1. Grebely J, Page K, Sacks-Davis R, van der Loeff MS, Rice TM, Bruneau J et al. The effects of female sex, viral genotype, and IL28B genotype on spontaneous clearance of acute hepatitis $\mathrm{C}$ virus infection. Hepatology. 2014;59(1):109-20. doi:10.1002/hep.26639. [PubMed: 23908124]

2. Hallager S, Brehm Christensen P, Ladelund S, Rye Clausen M, Lund Laursen A, Moller A et al. Mortality Rates in Patients With Chronic Hepatitis C and Cirrhosis Compared With the General Population: A Danish Cohort Study. J Infect Dis. 2017;215(2):192-201. doi:10.1093/infdis/jiw527. [PubMed: 27803168]

3. Ly KN, Hughes EM, Jiles RB, Holmberg SD. Rising Mortality Associated With Hepatitis C Virus in the United States, 2003-2013. Clin Infect Dis. 2016;62(10):1287-8. doi:10.1093/cid/ciw111. [PubMed: 26936668]

4. Suryaprasad AG, White JZ, Xu F, Eichler BA, Hamilton J, Patel A et al. Emerging epidemic of hepatitis $C$ virus infections among young nonurban persons who inject drugs in the United States, 2006-2012. Clin Infect Dis. 2014;59(10):1411-9. doi:10.1093/cid/ciu643. [PubMed: 25114031]

••5. Ly KN, Jiles RB, Teshale EH, Foster MA, Pesano RL, Holmberg SD. Hepatitis C Virus Infection Among Reproductive-Aged Women and Children in the United States, 2006 to 2014. Ann Intern Med. 2017;166(11):775-82. doi:10.7326/M16-2350. [PubMed: 28492929] Important CDC study indicating an alarming increase in young women with $\mathrm{HCV}$ and therefore infants at risk for transmission.

•6. AASLD-IDSA HCV Guidance Panel. Hepatitis C Guidance 2018 Update: AASLD-IDSA Recommendations for Testing, Managing, and Treating Hepatitis C Virus Infection. Clin Infect Dis. 2018;67(10):1477-92. doi:10.1093/cid/ciy585. [PubMed: 30215672] Important consensus guidelines by two major specialty societies providing immediate guidance for clinicians regarding the testing, management, and care for those living with $\mathrm{HCV}$. 
7. Society for Maternal-Fetal Medicine, Hughes BL, Page CM, Kuller JA. Hepatitis C in pregnancy: screening, treatment, and management. Am J Obstet Gynecol. 2017;217(5):B2-B12. doi:10.1016/ j.ajog.2017.07.039.

8. Centers for Disease C, Prevention. Hepatitis C virus infection among adolescents and young adults:Massachusetts, 2002-2009. MMWR Morb Mortal Wkly Rep. 2011;60(17):537-41. [PubMed: 21544042]

9. Rosenberg ES, Rosenthal EM, Hall EW, Barker L, Hofmeister MG, Sullivan PS et al. Prevalence of Hepatitis C Virus Infection in US States and the District of Columbia, 2013 to 2016. JAMA Netw Open. 2018;1(8):el86371. doi:10.1001/jamanetworkopen.2018.6371.

10. Salemi JL, Spooner KK, Mejia de Grubb MC, Aggarwal A, Matas JL, Salihu HM. National trends of hepatitis B and C during pregnancy across sociodemographic, behavioral, and clinical factors, United States, 1998-2011. J Med Virol. 2017;89(6):1025-32. doi:10.1002/jmv.24725. [PubMed: 27805270]

11. Centers for Disease C, Prevention. Notes from the field : hepatitis $C$ virus infections among young adults—rural Wisconsin, 2010. MMWR Morb Mortal Wkly Rep. 2012;61(19):358. [PubMed: 22592276]

12. Cicero TJ, Ellis MS, Surratt HL, Kurtz SP. The changing face of heroin use in the United States: a retrospective analysis of the past 50 years. JAMA Psychiatry. 2014;71(7):821-6. doi: 10.1001/ jamapsychiatry.2014.366. [PubMed: 24871348]

13. Zibbell JE, Iqbal K, Patel RC, Suryaprasad A, Sanders KJ, Moore-Moravian L et al. Increases in hepatitis $\mathrm{C}$ virus infection related to injection drug use among persons aged $</=30$ years Kentucky, Tennessee, Virginia, and West Virginia, 2006-2012. MMWR Morb Mortal Wkly Rep. 2015;64(17):453-8. [PubMed: 25950251]

14. Esmaeili A, Mirzazadeh A, Carter GM, Esmaeili A, Hajarizadeh B, Sacks HS et al. Higher incidence of HCV in females compared to males who inject drugs: A systematic review and metaanalysis. J Viral Hepat. 2017;24(2):117-27. doi:10.1111/jvh.12628. [PubMed: 27790803]

-15. Esmaeili A, Mirzazadeh A, Morris MD, Hajarizadeh B, Sacks HS, Maher L et al. The Effect of Female Sex on Hepatitis C Incidence Among People Who Inject Drugs: Results From the International Multicohort lnC3 Collaborative. Clin Infect Dis. 2018;66(1):20-8. doi:10.1093/cid/ cix768. [PubMed: 29020200] An analysis of various cohorts across continents indicating that females who inject drugs may be at higher risk than males to be infected with $\mathrm{HCV}$

16. Marsh JC, Park K, Lin YA, Bersamira C. Gender differences in trends for heroin use and nonmedical prescription opioid use, 2007-2014. J Subst Abuse Treat. 2018;87:79-85. doi:10.1016/ j.jsat.2018.01.001. [PubMed: 29433788]

-17. Watts T, Stockman L, Martin J, Guilfoyle S, Vergeront JM. Increased Risk for Mother-to-Infant Transmission of Hepatitis C Virus Among Medicaid Recipients - Wisconsin, 2011-2015. MMWR Morb Mortal Wkly Rep. 2017;66(42):1136-9. doi:10.15585/mmwr.mm6642a3. [PubMed: 29072864] CDC report indicating increasing risk for perinatal transmission of HCV

18. Rossi RM, Warshak CR. Prevalence of Maternal Hepatitis C Virus Infection in Ohio. Obstet Gynecol. 2018;132(3):708-16. doi:10.1097/AOG.0000000000002807. [PubMed: 30095786]

19. Patrick SW, Bauer AM, Warren MD, Jones TF, Wester C. Hepatitis C Virus Infection Among Women Giving Birth - Tennessee and United States, 2009-2014. MMWR Morb Mortal Wkly Rep. 2017;66(18):470-3. doi:10.15585/mmwr.mm6618a3. [PubMed: 28493860]

20. Espinosa CM, Jhaveri R. Update on the management of hepatitis B and C infections in the neonatal period. Semin Perinatol. 2018;42(3):185-90. doi:10.1053/j.semperi.2018.02.006. [PubMed: 29526383]

21. Modin L, Arshad A, Wilkes B, Benselin J, Lloyd C, Irving WL et al. Epidemiology and natural history of hepatitis $\mathrm{C}$ virus infection among children and young people. J Hepatol. 2018. doi: 10.1016/j.jhep.2018.11.013.

22. Delgado-Borrego A, Smith L, Jonas MM, Hall CA, Negre B, Jordan SH et al. Expected and actual case ascertainment and treatment rates for children infected with hepatitis $\mathrm{C}$ in Florida and the United States: epidemiologic evidence from statewide and nationwide surveys. J Pediatr. 2012;161(5):915-21. doi:10.1016/j.jpeds.2012.05.002. [PubMed: 22765955] 
$\bullet$ 23. Kuncio DE, Newbern EC, Johnson CC, Viner KM. Failure to Test and Identify Perinatally Infected Children Born to Hepatitis C Virus-Infected Women. Clin Infect Dis. 2016;62(8):980-5. doi:10.1093/cid/ciw026. [PubMed: 26797211] An important study documenting the inability to identify pregnant women with $\mathrm{HCV}$ via risk-factor based screening

24. Chappell CA, Hillier SL, Crowe D, Meyn LA, Bogen DL, Krans EE. Hepatitis C Virus Screening Among Children Exposed During Pregnancy. Pediatrics. 2018;141(6). doi:10.1542/peds. 2017-3273.

25. Wiese M, Grungreiff K, Guthoff W, Lafrenz M, Oesen U, Porst H. Outcome in a hepatitis C (genotype lb) single source outbreak in Germany--a 25-year multicenter study. J Hepatol. 2005;43(4):590-8. [PubMed: 16237783]

26. Di Martino V, Lebray P, Myers RP, Pannier E, Paradis V, Charlotte F et al. Progression of liver fibrosis in women infected with hepatitis C: long-term benefit of estrogen exposure. Hepatology. 2004;40(6):1426-33. doi:10.1002/hep.20463. [PubMed: 15565616]

27. Sarkar M, Dodge JL, Greenblatt RM, Kuniholm MH, DeHovitz J, Plankey M et al. Reproductive Aging and Hepatic Fibrosis Progression in Human Immunodeficiency Virus/Hepatitis C VirusCoinfected Women. Clin Infect Dis. 2017;65(10):1695-702. doi:10.1093/cid/cix643. [PubMed: 29020239]

28. Pergam SA, Wang CC, Gardella CM, Sandison TG, Phipps WT, Hawes SE. Pregnancy complications associated with hepatitis C: data from a 2003-2005 Washington state birth cohort. Am J Obstet Gynecol. 2008;199(1):38 e1-9. doi:10.1016/j.ajog.2008.03.052. [PubMed: 18486089]

29. Huang QT, Hang LL, Zhong M, Gao YF, Luo ML, Yu YH. Maternal HCV infection is associated with intrauterine fetal growth disturbance: A meta-analysis of observational studies. Medicine (Baltimore). 2016;95(35):e4777. doi:10.1097/MD.0000000000004777. [PubMed: 27583932]

30. Wijarnpreecha K, Thongprayoon C, Sanguankeo A, Upala S, Ungprasert P, Cheungpasitporn W. Hepatitis $\mathrm{C}$ infection and intrahepatic cholestasis of pregnancy: A systematic review and metaanalysis. Clin Res Hepatol Gastroenterol. 2017;41(1):39-45. doi:10.1016/j.clinre.2016.07.004. [PubMed: 27542514]

31. Conte D, Fraquelli M, Prati D, Colucci A, Minola E. Prevalence and clinical course of chronic hepatitis $\mathrm{C}$ virus (HCV) infection and rate of $\mathrm{HCV}$ vertical transmission in a cohort of 15,250 pregnant women. Hepatology. 2000;31(3):751-5. doi:10.1002/hep.510310328. [PubMed: 10706568]

32. Honegger JR, Kim S, Price AA, Kohout JA, McKnight KL, Prasad MR et al. Loss of immune escape mutations during persistent $\mathrm{HCV}$ infection in pregnancy enhances replication of vertically transmitted viruses. Nat Med. 2013;19(11):1529-33. doi:10.1038/nm.3351. [PubMed: 24162814]

33. Hashem M, Jhaveri R, Saleh DA, Sharaf SA, El-Mougy F, Abdelsalam L et al. Spontaneous Viral Load Decline and Subsequent Clearance of Chronic Hepatitis C Virus in Postpartum Women Correlates With Favorable Interleukin-28B Gene Allele. Clin Infect Dis. 2017;65(6):999-1005. doi:10.1093/cid/cix445. [PubMed: 28903504]

34. Food and Drug Administration. Harvoni Package Insert. https://www.accessdata.fda.gov/ drugsatfdadocs/label/2015/205834s001lbl.pdf. Accessed January 28, 20192015.

35. Food and Drug Administration. Epclusa Package Insert. https://www.accessdata.fda.gov/ drugsatfdadocs/label/2016/208341s000lbl.pdf. Accessed: January 15, 2019.

36. Food and Drug Administration. Daklinza Package Insert. https://www.accessdata.fda.gov/ drugsatfdadocs/label/2017/206843s006lbl.pdf. Accessed January 28, 2019. .

37. Food and Drug Administration. Mavyret Package Insert. https://www.accessdata.fda.gov/ drugsatfdadocs/label/2017/209394s000lbl.pdf. Accessed: February 8, 2018.

38. Kushner T, Cohen J, Tien PC, Terrault NA. Evaluating Women's Preferences for Hepatitis C Treatment During Pregnancy. Hepatol Commun. 2018;2(11):1306-10. doi:10.1002/hep4.1264. [PubMed: 30411077]

39. Gilbert EM, Darin KM, Scarsi KK, McLaughlin MM. Antiretroviral Pharmacokinetics in Pregnant Women. Pharmacotherapy. 2015;35(9):838-55. doi:10.1002/phar.1626. [PubMed: 26297552]

40. United States Department of Health and Human Services, Food and Drug Administration Center for Drug Evaluation and Research. Guidance for Industry: Pharmacokinetics in Pregnancy - Study 
Design, Data Analysis, And Impact on Dosing and Labeling. 102004 https://www.fda.gov/ downloads/Drugs/.../Guidances/ucm072133.pdf. Accessed on February 8, 2018.

41. US National Institutes of Health, US National Library of Medicine. Study of hepatitis C treatment during pregnancy. Available at: https://clinicaltrials.gov/ct2/show/NCr02683005. Accessed January 29, 2019.

• 42. Chappell CA, Krans EE, Bunge K, Macio I, Bogen D, Scarsi KK et al., editors. A Phase One Study of Ledipasvir/sofosbuvir in Pregnant Women with Hepatitis C Virus. Abstract \#87 Conference on Retroviruses and Opportunistic Infections, Seattle, Washington, 2019 ; 2019; Seattle, Washington.First study showing initial safety and outcomes of DAA treatment in 8 pregnant women.

43. Robaeys G, Bielen R, Azar DG, Razavi H, Nevens F. Global genotype distribution of hepatitis C viral infection among people who inject drugs. J Hepatol. 2016;65(6):1094-103. doi:10.1016/ j.jhep.2016.07.042. [PubMed: 27520879]

44. Coyle C, Kwakwa H, Viner K. Integrating Routine HCV Testing in Primary Care: Lessons Learned from Five Federally Qualified Health Centers in Philadelphia, Pennsylvania, 2012-2014. Public Health Rep. 2016;131 Suppl 2:65-73. doi:10.1177/00333549161310S211. [PubMed: 27168664]

45. Centers for Disease C. Prevention of perinatal transmission of hepatitis B virus: prenatal screening of all pregnant women for hepatitis B surface antigen. MMWR Morb Mortal Wkly Rep. 1988;37(22):341-6, 51. [PubMed: 2967425]

46. Alberti A, Noventa F, Benvegnu L, Boccato S, Gatta A. Prevalence of liver disease in a population of asymptomatic persons with hepatitis C virus infection. Ann Intern Med. 2002;137(12):961-4. [PubMed: 12484711]

•47. Fernandez N, Towers CV, Wolfe L, Hennessy MD, Weitz B, Porter S. Sharing of Snorting Straws and Hepatitis C Virus Infection in Pregnant Women. Obstet Gynecol. 2016;128(2):234-7. doi: 10.1097/AOG.0000000000001507. [PubMed: 27400008] Study from Kentucky with finding that snorting drugs may be an important risk factor for acquiring HCV among women.

48. Boudova S, Mark K, El-Kamary SS. Risk-Based Hepatitis C Screening in Pregnancy Is Less Reliable Than Universal Screening: A Retrospective Chart Review. Open Forum Infect Dis. 2018;5(3):ofy043. doi:10.1093/ofid/ofy043. [PubMed: 29564364]

49. Kuncio DE, Newbern EC, Fernandez-Vina MH, Herdman B, Johnson CC, Viner KM. Comparison of risk-based hepatitis $\mathrm{C}$ screening and the true seroprevalence in an urban prison system. Journal of urban health : bulletin of the New York Academy of Medicine. 2015;92(2):379-86. doi: 10.1007/s11524-015-9945-4. [PubMed: 25795212]

50. Roblin DW, Smith BD, Weinbaum CM, Sabin ME. HCV screening practices and prevalence in an MCO, 2000-2007. Am J Manag Care. 2011;17(8):548-55. [PubMed: 21851142]

51. Page K, Leeman L, Bishop S, Cano S, Bakhireva LN. Hepatitis C Cascade of Care Among Pregnant Women on Opioid Agonist Pharmacotherapy Attending a Comprehensive Prenatal Program. Matern Child Health J. 2017;21(9):1778-83. doi:10.1007/s10995-017-2316-x. [PubMed: 28699096]

52. Chasnoff IJ, Landress HJ, Barrett ME. The prevalence of illicit-drug or alcohol use during pregnancy and discrepancies in mandatory reporting in Pinellas County, Florida. N Engl J Med. 1990;322(17):1202-6. doi:10.1056/NEJM199004263221706. [PubMed: 2325711]

53. Garg M, Garrison L, Leeman L, Hamidovic A, Borrego M, Rayburn WF et al. Validity of SelfReported Drug Use Information Among Pregnant Women. Matern Child Health J. 2016;20(1):417. doi:10.1007/s10995-015-1799-6. [PubMed: 26175273]

-54. Waruingi W, Mhanna MJ, Kumar D, Abughali N. Hepatitis C Virus universal screening versus risk based selective screening during pregnancy. J Neonatal Perinatal Med. 2015;8(4):371-8. doi: 10.3233/NPM-15915024. [PubMed: 26836823] A study indicating that risk-based screening is ineffective

••55. Rose M, Myers J, Evans J, Prince A, Espinosa C, editors. Abstract 87: Hepatitis C risk-based vs. universal screening among pregnant women: implementation and cost-effectiveness analysis. The Liver Meeting; 2018 November 11; San Francisco, CA.Demonstration project indicating 20-fold increase in identifying pregnant women by implementation of universal screening for HCV; also indicates cost-effectiveness. 
56. Krans EE, Rothenberger SD, Morrison PK, Park SY, Klocke LC, Turocy MJ et al. Hepatitis C Virus Knowledge Among Pregnant Women with Opioid Use Disorder. Matern Child Health J. 2018;22(8): 1208-16. doi:10.1007/s10995-018-2506-1. [PubMed: 29500784]

57. Boaz K, Fiore AE, Schrag SJ, Gonik B, Schulkin J. Screening and counseling practices reported by obstetrician-gynecologists for patients with hepatitis $\mathrm{C}$ virus infection. Infectious diseases in obstetrics and gynecology. 2003;11(1):39-44. doi:10.1155/S106474490300005X. [PubMed: 12839631]

58. Giles ML, Garland SM, Grover SR, Lewin SM, Hellard ME. Impact of an education campaign on management in pregnancy of women infected with a blood-borne virus. Med J Aust. 2006;184(8): 389-92. [PubMed: 16618237]

59. National Viral Hepatitis Roundtable and Center for Health Law \& Policy Innovation. Hepatitis C: the state of Medicaid access 2017 national summary report.

•60. Tasillo A, Eftekhari Yazdi G, Nolen S, Schillie S, Vellozzi C, Epstein R et al. Short-Term Effects and Long-Term Cost-Effectiveness of Universal Hepatitis C Testing in Prenatal Care. Obstet Gynecol. 2019. doi:10.1097/AOG.0000000000003062.Modeling study indicating that universal screening would capture more cases of $\mathrm{HCV}$ and that this approach would be cost-effective compared to current standards of risk-factor based screening.

-61. Chaillon A, Rand EB, Reau N, Martin NK. Cost-effectiveness of Universal Hepatitis C Virus Screening of Pregnant Women in the United States. Clinical Infectious Diseases (Accepted, in press). 2019.Another modeling study which also indicates the cost-effectiveness of universal screening of $\mathrm{HCV}$; indicates that this approach would be even more cost-effective if more infants were properly tested.

62. Arora S, Thornton K, Murata G, Deming P, Kalishman S, Dion D et al. Outcomes of treatment for hepatitis C virus infection by primary care providers. N Engl J Med. 2011;364(23):2199-207. doi: 10.1056/NEJMoa1009370. [PubMed: 21631316]

63. Barua S, Greenwald R, Grebely J, Dore GJ, Swan T, Taylor LE. Restrictions for Medicaid Reimbursement of Sofosbuvir for the Treatment of Hepatitis C Virus Infection in the United States. Ann Intern Med. 2015;163(3):215-23. doi:10.7326/M15-0406. [PubMed: 26120969] 
Table 1:

Key points regarding the transmission, epidemiology, natural history and treatment of hepatitis C virus (HCV) in pregnant women

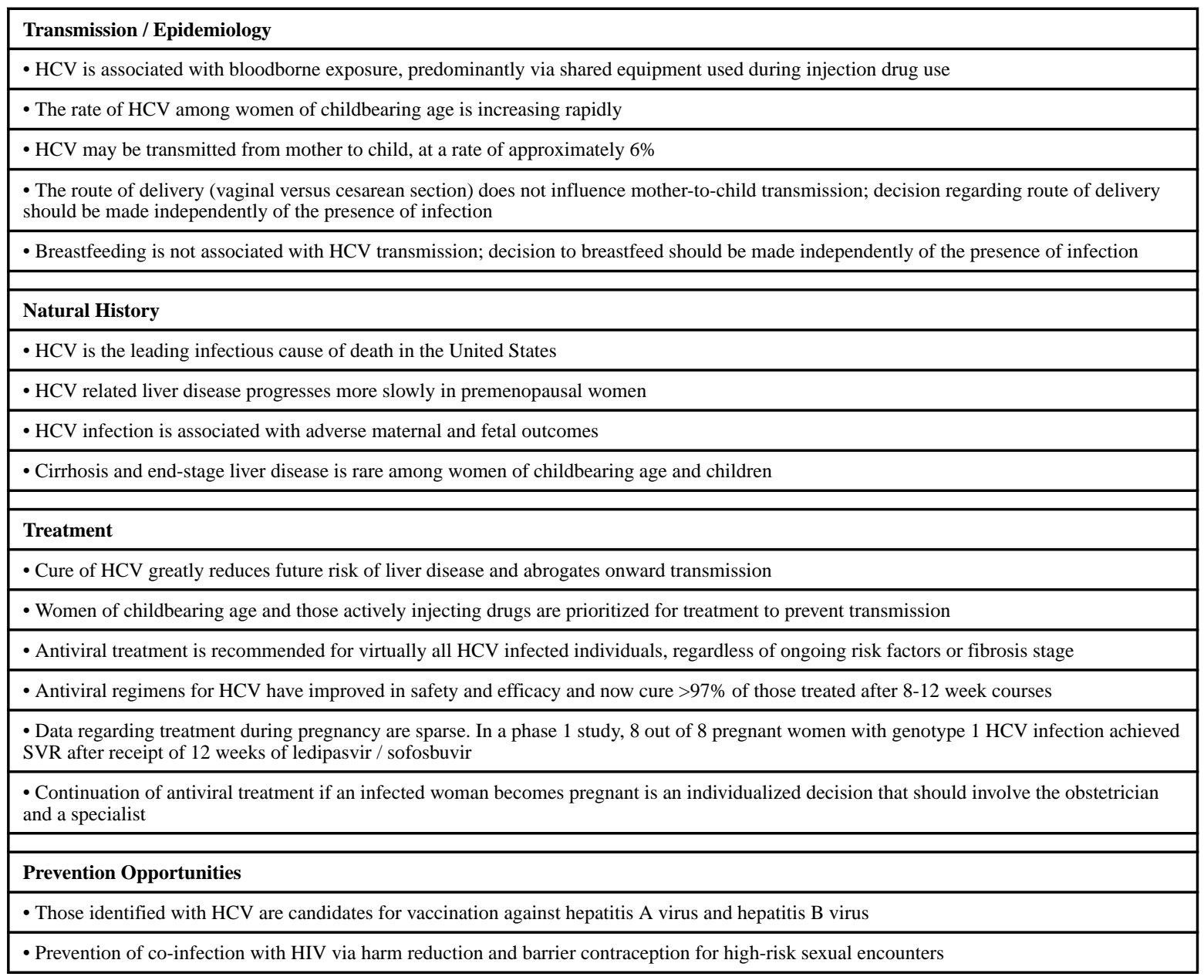


Table 2:

Women in whom prenatal screening for hepatitis $\mathrm{C}$ virus is recommended by the Society of Maternal Fetal Medicine (SMFM)[7] and the AASLD-IDSA Guidance Panel[6]

\begin{tabular}{|c|c|}
\hline \multicolumn{2}{|c|}{ Recommendations regarding prenatal screening for hepatitis $\mathrm{C}$ virus $(\mathrm{HCV})$ in the United States } \\
\hline SMFM & AASLD-IDSA Guidance \\
\hline Women who ever used injection or intranasal illegal drugs (even once) ${ }^{*}$ & \multirow[t]{8}{*}{ All pregnant women ideally at the initiation of prenatal care } \\
\hline Women ever on long-term hemodialysis & \\
\hline $\begin{array}{l}\text { Women with percutaneous/parenteral exposures in unregulated setting (eg, } \\
\text { tattoos received outside of licensed parlors or medical procedures done in } \\
\text { settings without strict infection control policies) }\end{array}$ & \\
\hline $\begin{array}{l}\text { Recipients of transfusions or organ transplants before July } 1992 \text { and recipients } \\
\text { of clotting factor concentrates produced before } 1987\end{array}$ & \\
\hline Recipients of blood products from donor who later tested positive for HCV & \\
\hline Women with history of incarceration & \\
\hline $\begin{array}{l}\text { Women seeking evaluation or care for sexually transmitted infection, including } \\
\text { HIV }\end{array}$ & \\
\hline $\begin{array}{l}\text { Women with unexplained chronic liver disease (including persistently elevated } \\
\text { ALT) }\end{array}$ & \\
\hline
\end{tabular}

Abbreviations: ALT, alanine aminotransferase; HIV, human immunodeficiency virus

Women with ongoing injection or intranasal drug use should have repeat screening in the third trimester 
Table 3:

Issues with universal screening of pregnant women for $\mathrm{HCV}$

\begin{tabular}{|l|l|}
\hline Universal testing issue & Recommendation \\
\hline Testing characteristics & \\
\hline False positives & Provider and patient education \\
\hline Additional visit / blood draw & $\begin{array}{l}\text { May be "bundled" with HIV and HCV testing } \\
\text { Use of "reflex" testing reduces visits }\end{array}$ \\
\hline Stigma of testing & Routinizing testing should reduce stigma \\
\hline & \\
\hline Provider time & Routinizing testing reduces provider time spent \\
\hline Lack of provider knowledge & Education \\
\hline Added cost & Implementation is within cost-effectiveness thresholds for improving quality-adjusted life-years \\
\hline Low rate of testing infants & Improved communication between maternal care team and pediatricians, public health follow-up \\
\hline
\end{tabular}

Curr Hepatol Rep. Author manuscript; available in PMC 2020 June 01. 